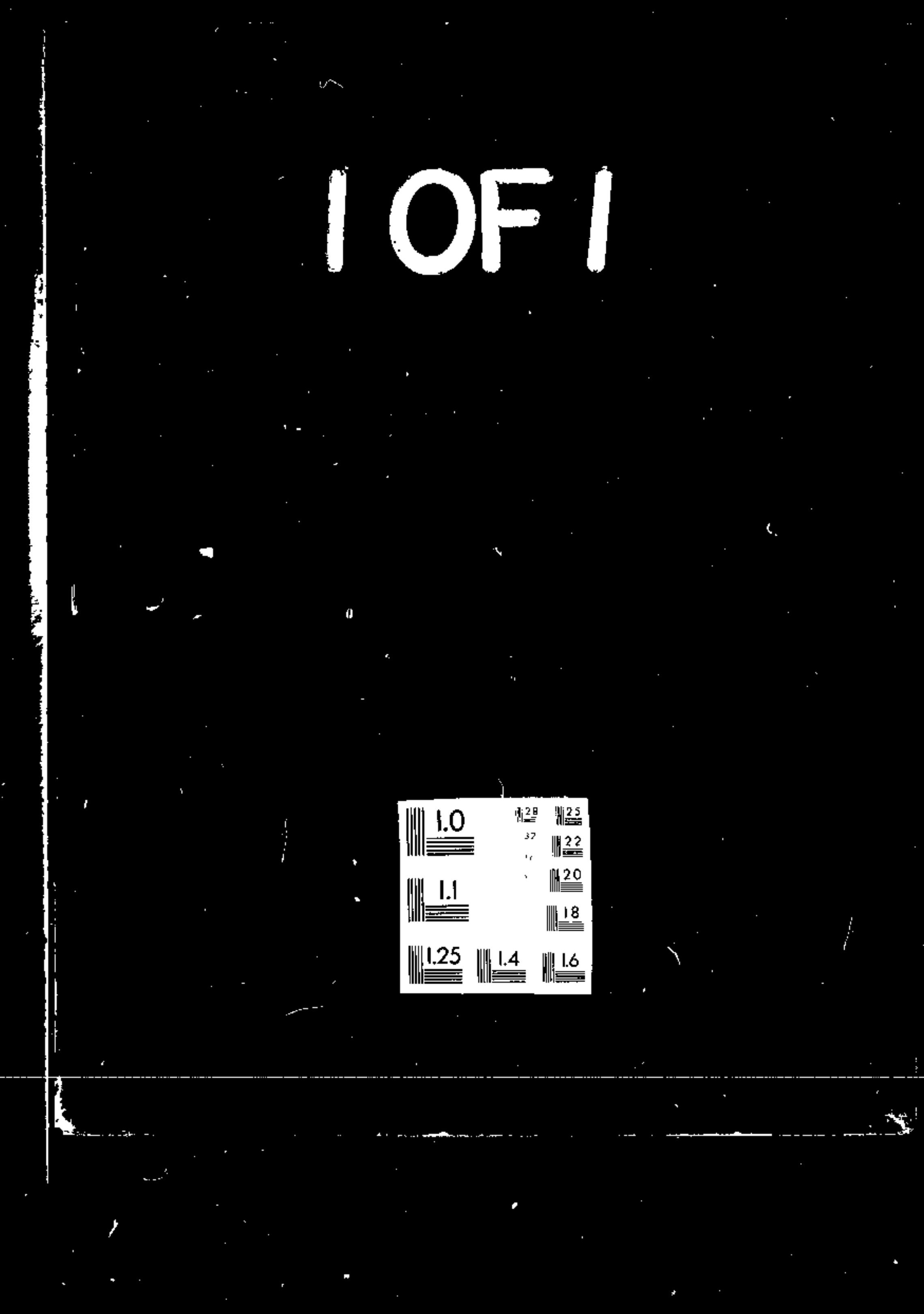




\section{Summary of the Physics Opportunities Working Group}

\section{Pisin Chen}

Stanford Lineor Accelemator Center Stanfort University, Stanford, Califarmia 9fsog

$\mathrm{STAC}-\mathrm{H} / 3-6 \mathrm{D22}$

0893006903

\section{KLRK T. MCDOnald}

Joseph Henry Leboratories,

Princeton University, Princeton, NJ 08544

\section{ABSTRACT}

The Physics Opportmaities Working Group was convened with the rather general mandate to explore physics opportunities that may arise is nen accelerator terchnolojes and facilities come into play. Five topics were considered duriag the workshop: OED at critical field otrength, povel positron cources, erystal accelerators, supprestion of benurntrablung, and musp colliders. Of particular interest was the eense that a high enerby muon collider might be technically feasible and certainly deserve oterious study.

\section{INTRODUCTION}

A Working Group was convened wilb the sather general mandate to explore puysice opportunities that may arise as new accelerator technologies and tacilities curne into play. The sfenda was set by the interests of the participants, d) many of whom were inspired to give extemporageous nresentations of ideas they had nol experted to discrss, bul which ideas had boen quielly nurtured awaitiog a forum such as this Working Group. The working growp considered five topics:

1. QED at critical field gtreogtb.

2. Novel positron sources.

3. Crystal accelerators.

4. Suppression of beamstrablung.

5. Musn colliders.

In the following we attempl to give a faros of the discussion on tach of these topics.

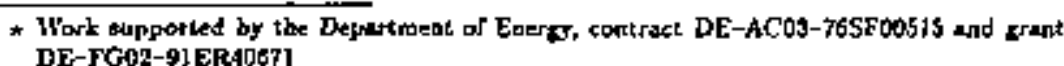

QED AT CHITICAL FIELD STAENGTH

K. MeDonald reviewed how the combination of low-emittance bigb-energy elecnon beams with Isbletop teraWait lasers offers the opportunity to explore QED beyond the critieal field strength.

$$
E_{\mathrm{cnl}}=\frac{\mathrm{m}^{2} \mathrm{c}^{\mathrm{J}}}{\mathrm{e} h} \approx 10^{16} \mathrm{~V} / \mathrm{cm}
$$

at which the vacuurn is unstable againgt pair creation. A spectlative possibility is thal a QED phase change occurs that could lead to struclure in the $t^{+} e^{-}$mass spectrum related to the posjtran peaks reported in beary-jon colligiens at Darmstadl.

A. Varfolomeer recalled that terabiatl lasera could lead to a demonstration of jight-by-light gcatteriog uging the techrique of four-wave mixiog. A nolt discussing this furthes appears in these proteclings.

A major theme of the Workjog Group was the production of high-quality, tigh. energy lepton-lepton collisions in luture accelerstors. It is anticipated that it will be difficalt to majplain a well-defined center-of.mass energy in $e^{+} e^{-}$collision once the electromagnetic fields of a bunch exceed the QED critical field as abserved from the oncoming bunch. The reulting radiation is generally callepd beametrahjung.

P. Chen reviewed three aspects of beamatrahlung that will limit the performance of future $e^{t} e^{-}$calliders. First, the bunches on the average radiale a substantid fraction of their energy once the 50-called bearntrablung parameter

$$
\Upsilon=\frac{2\} E_{\text {buseb }}}{E_{\text {crit }}} \sim 1 \text {. }
$$

Nievertheless, a good fraction of the bunch paricles remain at the initial energy, thanks to the quantum nature of the radiation. For example, with $E_{\text {cm }}=500 \mathrm{CeV}$ and $Y=0.12$ some $70 \%$ of the $e^{+} e^{-}$collisions still have urore thad $98 \%$ of the nomital centet-of-mast entergy, although the average energy loss per bean particle is $10 \%$. However, running with $Y$ much bigber than this value pould result in a spread of center-of-mass energies rather like that for quark-quark and gluon-gluon scatterigg at a badron collider.

Sreond, crice $\mathrm{I} \geqslant 1$ there is copious production of $e^{+} \varepsilon^{-}$pair by a two-stage process, as discussed earlier. ${ }^{13}$ The tate are sn extremely rapid function of $Y$ so the pair creation is negligible for $T<0.2$. Third, the light-by.light scattering processes that lead to $e^{+} e^{-}$pair creation also lead to gluon-gluon and quark-aptiquark pair cteation. The most annoying feature of this is radiation of soft-ginan jets ("minijets") which spew low- $P_{t}$ badrong inta the colligion region. "While only a few percent of the collisions lead to minijets for $T \approx I$, the number of low-Pt particles in such events is large. Any deteclor must be effectively blind to these particles, which may compramise the capability for low-P, physics which has been such a ricb sourte in present $\varepsilon^{+} \varepsilon^{-}$machines. 


\section{NOVEL POSITRON SOURCES}

Tbe copious produrtion of positrons at crittcal field strength might be an excellent source of positrons for future linear colltdirs an a proposal by $\mathbf{F}$ Chen and $F$ Palner In c laser collisiors the QED st roug Keld processes became prominent once parameter is where

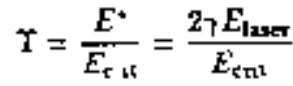

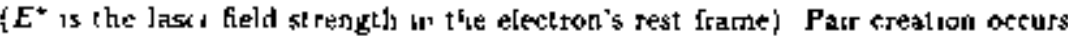
in a tho slej process laser photons collde mith high eperg electrons lo produce figkt energi bachscatiered ptotuns liter the high energs photons collude with laser f hotors ro produre e $\epsilon^{-}$posis

For $Y>1$ the interaction probubslit? approaches unity, and the created positsous and electrons resuten act wath ithe laser to produce an electromagnelic cascade There ate tro important aspects un sucli an afproach First, there exusts a threshold at $r \sim 1$ in the colseteth pais creation process This helps to arcuntulate positrom at a lou, but finte, energy wnt a small energ bits Second a remarkable fact

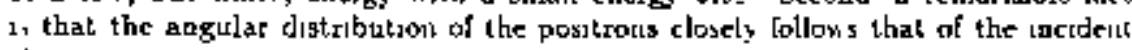
electrolts, I 2 gcomeinic emittance 15 preserved But since the posstrons hase much lijwer energs theje intariant emuttance is tomer than that of the electrons That 15 "rooling automatically occurs'

Ir a optical laser is to be used, the inulat electron energ is optimized at 250 (ie) Io use $50 \mathrm{Gel}$ electrons the laser should lase $\approx 40 \mathrm{am}$ wa.elength This strong motuation for a far UV free etertrou laser program at SLAC

P Channell and D Cluc presented two wasiations on uzheres for production of

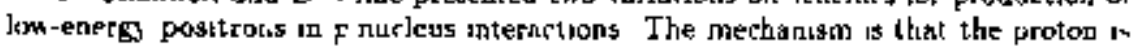
absorbed by the nucleus,

$$
p+(Z, A) \rightarrow(Z+1, A)+7,
$$

"hieh ther decass wa posturon emission

$$
(Z+1 \vee\} \rightarrow\{Z, M+1)+\epsilon^{+}
$$

For 5 MIeV protons the capture cross accuons are of order $300 \mathrm{nb}, \cdot \cdot \mathrm{d}$ the beth

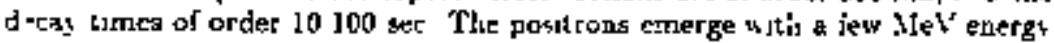

For high production rates the target must be demge, but for efficsent postron e atraction the $(Z+1, N)$ nucle, should be in a difuse medium Hence the $(Z+1, A)$ n xsles must be separated from the $\left(Z\right.$ b) nuclet $v_{1}$ a chemucal or isotope separation The $(Z+1, N)$ nucien could then be storod in a magnetic bottle unt 1 they decal

Small scalc vergions of such s scheme are presently implemented as sourcer for prasitron emission tamographs Significant $R A D$ is requied to achseve produrtion tates of $10^{14} /$ sec as desired for high energs pbysics

\section{CRYSTAL ACGELERATORS}

W Gabella ren iewed suggestions for plasma accelprators un cristals ${ }^{\text {in }}$ Here the plasmi, consists of the conduction ctectrons of the eryalal In one echeme a Bcoustic

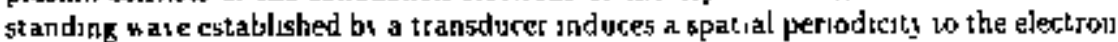
density Then a purnp laser whose warclength is the sar $e$ ws that of the acoustic wave evestes electrons into a plasma oscilfation "The crystal nust be largel) ttanspasent to the laser, so the platma frequency of the tristal efectrons must be less than the lase fiequency A (properly phased) clarged particle beam passing through the crystal cas then extract energ, from the plasma osctlint ons

The uac of a cristal 15 of unterest because of changelung uhich uorks best for posite ely charged particles in principle ucrs good emitance pieservation can be maistäned during accelezatson

It appeared that a demoustration of this teclinague roght be posable at the BXL

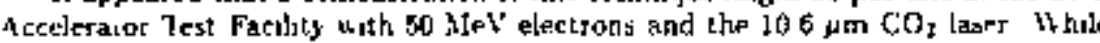
negatuvel charzed partucles suffer Coulomb collistons afier some distarce in a cry stal, acceleration orer a short distance should be feasuble The channeline capture angle was calculated to be 1 mrad at 50 klek, whtch ie nell matched to the emittanice of the ATF electron beam The frequenct of the $\mathrm{CO}_{2} \operatorname{lnger} 15 \mathrm{~L} \sim 2 \times 10^{14} \mathrm{~Hz}$ io the electron dengits in the instal must be $\sim 1 \mathrm{~B}^{12} / \mathrm{cm}^{j}(\Rightarrow$ arsenuc? $)$ The (tequency of the acoustic wase nould be about $300 \mathrm{MHz}$ For a laser intensity near the damagr

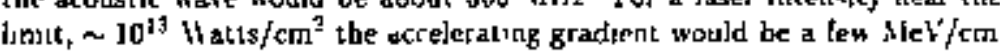

Another Echeme was prescated bs S Bchacz ${ }^{[1]}$ in which a cristat has a period, strain to form a hind of undulator Such a crsstal could be tlirn used un FEL and inverse FEL configurations but with charactersist was clengl ds much shorter than by other means

\section{BEAMSTHAHLUNG SUPPRESSION}

in this context ans addituonal mechanısms that could supprexs the bearnstrablung rould be most welcome \& Sessler revien ed a proposal for beamstrablung suppression usug a plasma at the ateraction point ${ }^{\text {[lat }}$ Arcordung to Lenz' las ke expect charge separation and return currents to be unduced in the plasma so as to cancel the $\mathbf{E}$ and $\mathbf{B}$ felds of the colliding bunches For good cancellation the bunch radus tnusl be murh smaller than the plosma anelongh, winch leads to the rosdition that the plosmo charge densiti must be much Jarger thatr that an the $\mathrm{e}^{\top} e^{-}$busthes For exarnple, at a vext Linear Colleder operating at $500 \mathrm{GeV}$ uth bunclues of $10^{\text {In }}$ particles eath I min long and $100 \mathrm{~nm}$ un radus, the electron denyly 15 of order $10^{21} / \mathrm{cm}^{3}$ Hence plasima density of order $10^{22} / \mathrm{cm}^{3}$ are needed Thas is a bugli number, but perhaps achuevable If so, calculation buegests that $90^{\prime \prime}$ of the beajpstrahlung could be suppressed

iv Barletta rew sened the possibulity of generating such plasma densities by laser excilation

Harever, as the energe of the $\mathrm{C}^{+} \mathrm{e}^{-}$collider suses, the luminosity must thcrease as o to mapran constant event fates, so the bunch size is likely to shmak This would require ever higher plastra densities for beamstrahlung suppressiog, and the scheme 
becomes difficult for energies of a few TeV or more. In addition, the use of high censity plasmes at the interaction point would introduce ita own kind of backgrounds such as high eaergy photons from bremsstrahlung.

J. Rooenzweig reviewed the issue of instabilities in plasma compensadion sebernes and compared these to alternatives based an 4-bean collisions (two pairs of comoving $t^{+} t^{-}$bunches) $)^{|\cdot| \mid}$ The conclusion is that plasma compensalion is more stable asainst dipole (kink) and quadrupole instabilities than s-beam schemes. The stability of lae latier can be improwed by tailoring the longitudinal charge-density profile of the Eunches.

P. Chanpell presented a rather speculative " $\varepsilon^{+} \varepsilon^{-}$plasma" compeasation ocheme i11 which plasm densities exceeding $10^{24} / \mathrm{cm}^{3}$ might be obtained by beamstrahlung $e^{+} e^{-}$pairs from auxiliary acceleralors.

P. Chen reviewed the Landaw-Poneranchuk-Migdal mechanism and other LPL4. like effects for suppression of radistion effects in beams. He noted that while the LPM effect ia not sufficient in suppressing these raidalions. the strong EM field of the opposing beam does belp to supprest bremgstrablung. [1"]

It appears that beamstrahlung remains a fundarnentad limit to performance of $e^{+} e^{-}$eolliders in the multi-TeV regime.

\section{MUON COLLIDERS}

The limiting effect of beamstrablung on future colliders makes it timely to roconsider the merits of muon colliders. ${ }^{[1,11]}$ From the definition (2) of the beamistrahlung parameter we sec that for muons beams of the tame enargy and bunch parameters as edectrona, $T$ will be ouly $1 / 205$ that Jas electrons. Without the disruptive effects of byamstrahlung, a muop collider would enjoy all the ndvaptages of a welli-defined putely leptonic initial states that bas made experimentation al electron colliders ctisper than that a hadron colliders.

D. Cline, and also D. Neuffer ${ }^{\prime \prime \prime]}$ reviewed the physics potential of manon colliders at the Higgs energy acale, 200 Gev-1 Tev. While production cross sections for quarks leptons and vector gauge bosons ate the same for clectron and muon bears, a muon collider has a major advantage over either electrons or hadrons lot production of Higgs bosons. Since the fatter comple to the mass of the spin-1/2 beam particles. puoduction of Higgs by muons in $\left(m_{\mu} / m_{t}\right)^{2}=4 \times 10^{4}$ lagger than by electrons Laminosities of only $10^{30} \mathrm{~cm}^{-2} \mathrm{sec}^{-1}$ would make a muon col]ider very competitive for Higes production.

R. Noble reviewed the prospects for high flux muons sources based on proton

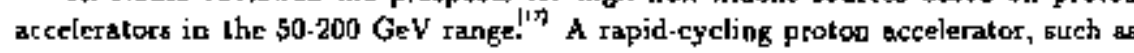
that considered for the TRIUWF II upgrade, could provide $10^{15}$ prolons/gec. This wint]d yield gome $10^{13}$ pions/sec into a 3 \% momentum bite. As the pions decay some $10^{12}$ muons/sec could be collected into an normalized emit tance of eN $\approx 10^{-3} \mathrm{~m} \cdot \mathrm{rad}$ These mupas have a total momentum s, read of about $40 \%$, so if the muon-mornent um spread is limited to $1 \%$, the yield wowld be $2.5 \times 10^{10}$ muons/sec, etr.
Various participants debated the option of muon production by slopping pions, with the conclusion that further otudieg are necded. In particular, there are subslantial differences belwetn positive. and negativemuon production from stopping pions.

Once a source exists, the muons must be accelerated, cooled, and brought into collision before they decay. Of course, the muons live longer at higher energy according to $T=7 \times 2.2 \times 10^{-6}$ sec. A wseful result is that the lifetime of muons moving in circles under the infucace of a fixed magnetic field is independent of the muon en. ergy. In particular, the lifetimes is conveniently expreased in the number of cormplete revolutions, or 'turns' as

$$
\text { muon lifetime in turns }=300 B[\text { Telsa] }
$$

For example, if 3.3-Tesla magnets are used throughout the accelerator, the mudn lifetione is 1000 lowat.

D. Neuffer ${ }^{|t| l \mid}$ and $A$. Ruggerio ${ }^{|t| 1}$ retiewed the luminosity requirements for a muon collider, usipg $1 \mathrm{TeV} \times 1 \mathrm{Tev}$ as an example:

$$
\mathcal{L}=\frac{N^{+} N^{-} f}{4 \pi \beta^{+} 6} \approx 10^{30} \mathrm{~cm}^{-2} \mathrm{~s}^{-1},
$$

where $N$ is the number of muons per bunch, $f$ is the bunch-calligion trequency, $g^{*}$ is the focusing slrengtb. and $c=c, N / r$ is the gromelric emittance. At $1 \mathrm{TeV}$ the muons have $y=10^{4}$, so their litetine is 20 ms. This suggests the gource should cycle at about $\approx 50 \mathrm{Fz}$. The collision region might be eitter aingie pase, or multiple pass in a atorage ring.

Mugn accelerators that include a storage ring to lake advantage of the potential 1000 turns of muou lifelime must face a new technical challenge. As the muons decay roughly $1 / 3$ of their energy is dumped into materif close to the ring io the form of electromsgnetic showers. For exanple, with $10^{13} 1$ TeV muons/sec in the ring, borne $10^{4}$ Watts must be dissipaled. For a ring of 1000 superconducting magnets, this is 10 Watts per magnel deposiled in a localized region of the coil unless precautions are taken.

Possible parameters for a muon Accelerator are then:

$$
\begin{aligned}
& \text { Single pass: } f=50 \mathrm{H}: \beta^{*}=5 \mathrm{~mm} . \\
& \text { Miultiple pass: } f=50 \times 1000 \text { turns }=4 \times 10^{4} ; \beta^{*}=5 \mathrm{~mm} . \\
& N^{+}=S^{m}=10^{\circ} \text { per cycle. }
\end{aligned}
$$

"hich leads to a requirement that the geometric emiltance be $10^{-10} \mathrm{~m}$. rad, and the normalized enitlance be $\epsilon_{N}=10^{-6} \mathrm{~m}$-rad. This is three orders of magnitude smallet thas tliat expected out of the muon source, so cooling is required, which thust be accoriplished in approxiriately' 1 msec. 
Two possible scherres for muon coolung were presented D Neuffer ${ }^{\mathrm{I} \cdot \mathrm{l}}$ reven ed the method of 'ienization cooling' in which muons pass through an absorber and lose both transrerse and longitudinal momentum to ionzakion, followed oy accelerating oictions to which che longitudraal momentum only is restored

A Rugegerio presented a new scheme based on stochastic coolog, concesued durng the Workshop ${ }^{[\omega]}$ In this the unuon bearn is busched into perhaps $50^{9}$ bunches of 10 particles each These bunches are transmitted I hrough a sertes of $(\approx 10)$ arcs s.parated by accelfrating sect tons In the arts stochastic coolung ts to be accomplusher u,th very bigh frequency pichups and aickers The luminossty dg achueved in single pass coltigions of each bunch The mugriant emrtence of each bunch must be icr. sinall $\left(\leqslant 10^{-16} \mathrm{~m}\right.$ rad) 10 this stherne

While the ionzation cooling scheme ss refatively conservative the stochastic collng scherne provohed lively discussions that contunue alter the Worhshop There rrinaned ver\} conssderable enthusiasm to understand the feanblity of muon acce $e$ ators in greater detarl, whsch lead to the formation of a new Worhshop for that purpose ${ }^{[\mathrm{bl}]}$

\section{HIGHLIGHTS}

The majot aliemes den elopet in cach of the five topics explared by the Hothing Group were

1 A proposed demonstration of induced light by lght sealtering with a three beam configuration of a tabletop teraWatt laser

2 A proposed low-emsttance high yıe]d posilron source at SLAC wa paur creatıon by light from a 50-om free electron laser

3 A proposed demonstration of a erystal accelterator at the BNL Accelerator Test Faclity

4 Reaftirnation that bearnstrablung is a severe limil to the performance of $e^{+} e^{-}$ collyders for $E_{\mathrm{rm}} \gtrsim 1 \mathrm{TeV}$

5 A muron callider based on an aggresswe cooling scheme that might provide the cleanest bugh-luminosity source for future high-energy phystcs

\section{REFERENCES}

I B Barletts A Bogaca, P Channell, P Chen, D Cline, P Debenham, B Gabella, A Jachson, G Jachson, $K$ Kirn, $N$ Kurnt, A Leledey, $K$ MeDon ald, F Mills, D Neuffer, R Noble, $R$ Palmer, I Pogorelsh\}, J Rogenzmetg, A Ruggerio, A Sessler, G Shutets, J Simpson, D Sutter, A Varfolomeev, $X$ Wang $J$ hi urtele

2 h T MrDonald et at Study of $O E D$ at Craticel Field Strength, th Workshop on beam Beam and Beaur Radiation Interactions Jigh Intensily and Nontinear Effects, ed by C Pellugna T hatsouleas and J Hosenz werg (World Scsentufic Sıngapore, 1992) p 127

3 K T Mebonald, Aduced Seatterting of Light by Light, these Praceedings

4 P Chen Drfferentıal Lummosty under hiultiphoton Btametrahlung, Pbys Res D46 (1992) 1186

5 P Chen and V L Telnow Cattrent Pais Crention in Limear Coltiders, Phys Rev Lett 83 (1989) 1796

6 MI Drees and $\mathrm{R} M$ Godbole, Ifentyets and Large Hadronze Bathgrounds if

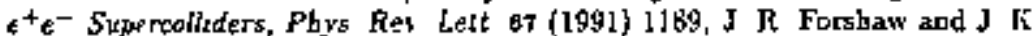
Storrow', The Mfitijet contrabution to the Total ete- Crass Section, Phys Lett B278 (1992) 193, P Chen, T Barhion and II E Peskin, Hadrante Prodiction

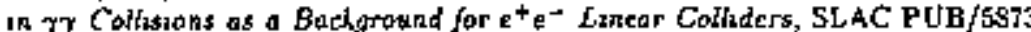
(1992) submulted so Phys Rev D

7 P Chen and R B Palmet, Coherent Pair Cieation as a Positron Source for Linear Colliders, these Proceedings

8 P Chen and $\mathrm{f}$ I Noble, Chontheled Purticle Acceleration by Plasma Wetes in Metals, hATO ASI Sertes B163 (1967) 517

9 I Katsouleas et al, A Side-Injected Plasma Atceltrator, TEEE Trans Nurl Sc1 INS-32 (1985) 3554

10 P Chen, D B Cline, and W E Gabelita Issues Regarding Acceleration in Crystats, these proveedings

11 S A Bogacz, Interse FEL Proton Accelerator usa Permodically Modalated Crystal Stractart, these Proceedings

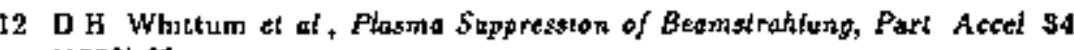
[1990) 89

13 J B Rosenzueng, B Autun and P Chen Instabilty of Compensated Beam-Beam Collustors, AlP Conf Proc 193 (1989) 32d

14 P Chen and S Klein, The Landes.Pomeranchuk-Aigdal Effect and Suppresston of Beanst rahlung and Bremsstrehilung in Lintar Colthders, these Procedings

15 A N Sknnshy, Accelertior end Inslmmentetion Prospects of Elementary Particle Phystes, AIP Couf Proe s6 (1980) 1056 
16. D. Neuffer, Princtiptes and Applications of Mwon Cooling, Part. Actel. 14 (1983) 75; Mudti-TeV Myor Colliders, AIP Conf. Proc. 156 (19g7) 201.

17. R.J. Noble, Particte Production and Sarvival in Meon Acceleration, these Proceedings.

LB. A.G. Fuggerio, The Muon Collider, these Proceedings.

19. Worshop on Muon Colliders: Particte Physics and Design (Napa Valley, Dec. 911, 1992) 

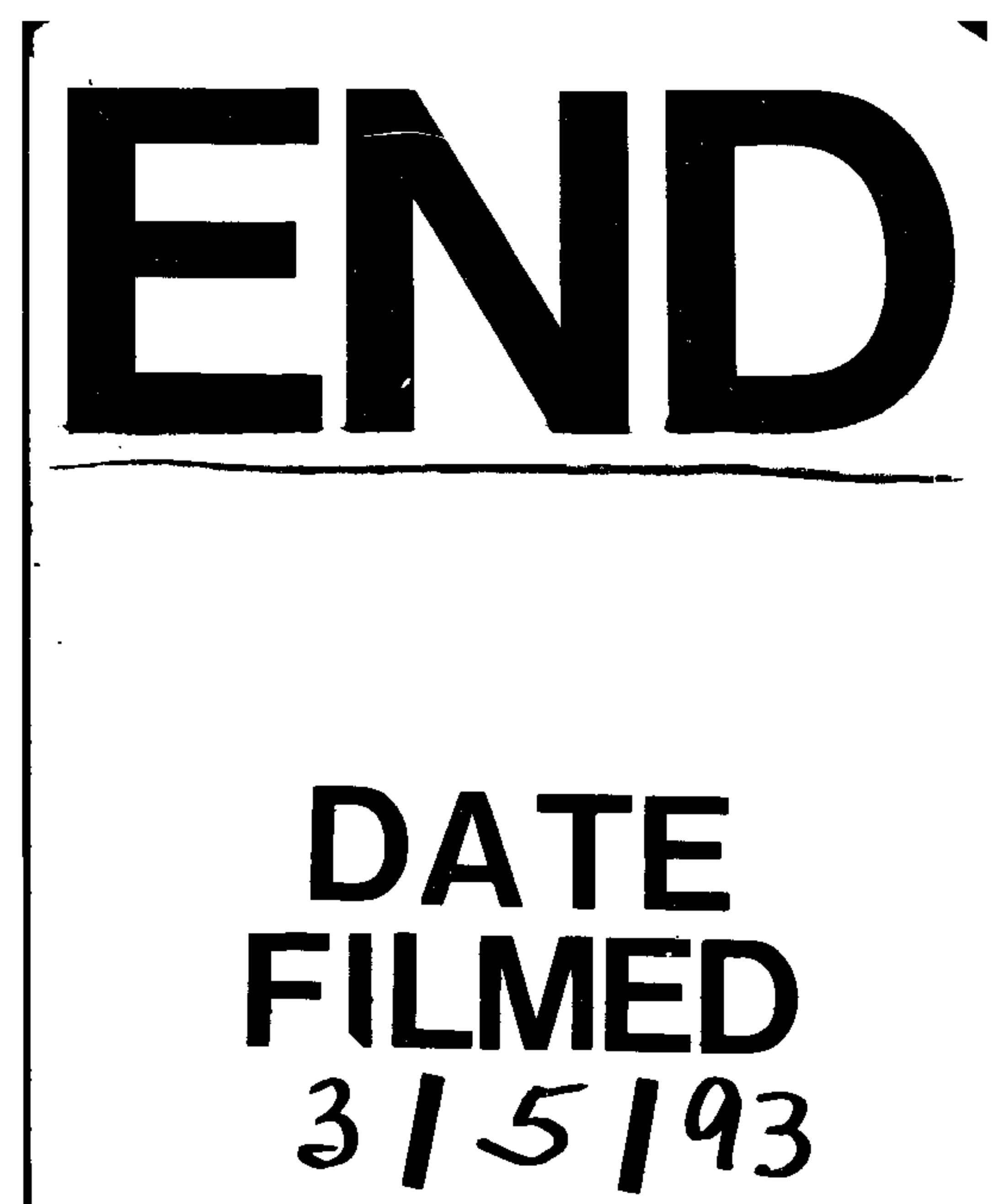

I 
